\title{
A New Structural Design Concept for Blended Wing Body Cabins
}

\author{
R. Vos ${ }^{1}$, F.J.J.M.M. Geuskens ${ }^{2}$, M.F.M. Hoogreef ${ }^{3}$ \\ Delft University of Technology, Kluyverweg 1, 2629HS Delft, the Netherlands
}

\begin{abstract}
This paper outlines a new concept for a pressure cabin design for blended-wing-body aircraft. An overview is presented of the wide oval cabin and why it is believed to be a possible alternative to existing designs of non-circular pressurized cabins. The perimeter of the oval cross section is formed by four smoothly connecting arcs of different radii. One arc forms the upper surface of the fuselage, one arc forms the lower surface, and two arcs at either side form the side of the fuselage. At the interconnection nodes of each of the arcs a prismatic box structure caries the tension and compression loads that result from pressurization. This structural layout forms a large uninterrupted internal space that allows for a flexible cabin configuration. Furthermore, this concept encompasses synergy in aerodynamic and structural design by having the lower member of the prismatic box structure forming the passenger floor and having the cabin outer skin panels be directly part of the aerodynamic shell. A method has been developed that estimates the weight of the cabin based on pressurization loads and main geometrical parameters of the cabin (height, span distribution, and length) as well as the geometry of the airfoil in the plane of symmetry of the cabin. A cabin design for $\mathbf{4 0 0}$ passengers shows a total cabin weight of $\mathbf{3 4}$ metric tons, and sufficient cargo volume for 36 LD3 containers.
\end{abstract}

\section{Introduction}

$\mathrm{T}$ HE reduction of fuel-consumption and noise is currently the highest priority in future aircraft design. The required fuel weight for a given mission range $(R)$ and payload weight $\left(W_{p}\right)$ depends on the operative empty weight $\left(W_{O E}\right.$ ), the propulsion characteristics (thrust-specific fuel consumption, $c_{j}$ ) and the aerodynamic efficiency $(L / D)$ of the aircraft. For jet aircraft one can use Breguet's range equation to show that the required fuel weight for the cruise part of the mission is:

$$
W_{F}=\left(W_{O E}+W_{p}\right) \frac{1-\xi}{\xi} \quad \text { with, } \quad \xi=\exp \left(\frac{-R c_{j}}{M a} \frac{1}{L / D}\right) .
$$

This equation intuitively shows the dependence of the fuel weight on the mission characteristics [including cruise Mach number $(M)$ and cruise altitude through the local speed of sound $(a)$ ] and the aforementioned performance characteristics. Reducing the operative empty weight and increasing the aerodynamic efficiency are the prime objectives for an airplane designer to reduce the fuel weight for a given mission. However, these quantities are intimately tied through the configuration design and require a careful trade-off if fuel is to be minimized. At the same time, constraints on field performance and handling characteristics are to be satisfied which influence both $W_{O E}$ and $L / D$.

\footnotetext{
${ }^{1}$ Assistant Professor, Faculty of Aerospace Engineering, AIAA member, R.Vos@tudelft.nl

${ }^{2}$ PhD Researcher Faculty of Aerospace Engineering, F.Geuskens@tudelft.nl

${ }^{3}$ MSc Student, Faculty of Aerospace Engineering, M.F.M.Hoogreef@student.tudelft.nl
} 
For long-range aircraft it is generally improvements in lift-to-drag ratio that have the highest effect on the fuel reduction. The Blended Wing Body (BWB) (Figure 1) has been extensively investigated over the past decades because it has been claimed it could increase the aerodynamic efficiency up to 27 [1]. The absence of a separate empennage in combination with the reduced wetted area are the most significant contributors in support of these claims. Apart from the aerodynamic advantages, also a structural advantage is expected over conventional tube-andwing (TAW) aircraft. The structural efficiency is improved due to a lower wing loading and a large inertia relief (see Figure 2) [2]. The bending moments in the wing structure and hence the empty weight of the aircraft are reduced because the planform weight distribution is close to the aerodynamic load distribution for BWB-aircraft. The main structural challenge for the BWB is to efficiently carry the pressurization loads during high-altitude cruise flight. The noncircular nature of the cabin cross section requires alternatives to the highly efficient circular shell structure of conventional TAW aircraft.

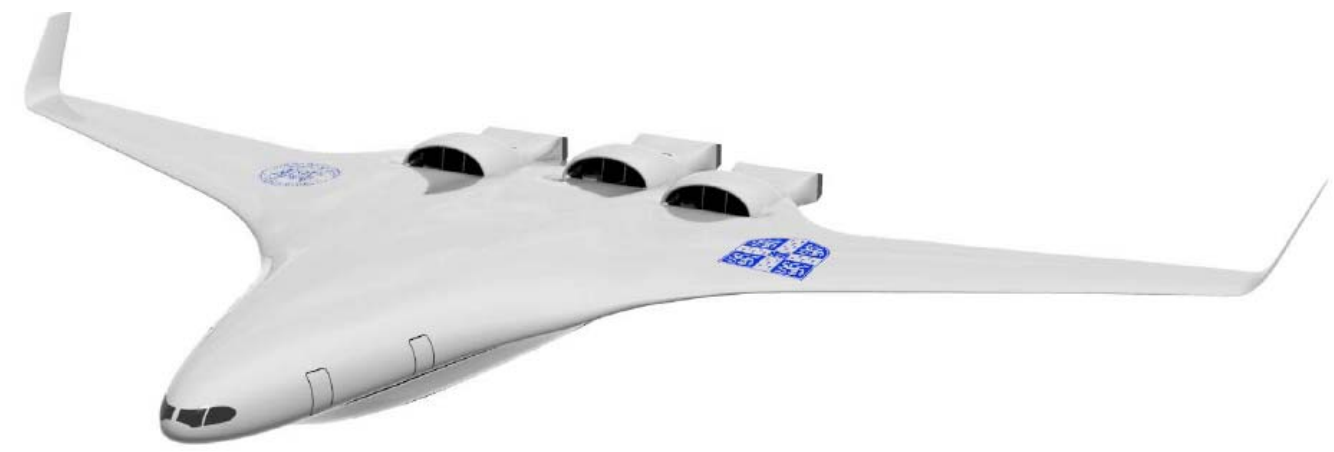

Figure 1. The Silent Aircraft BWB Design [3]

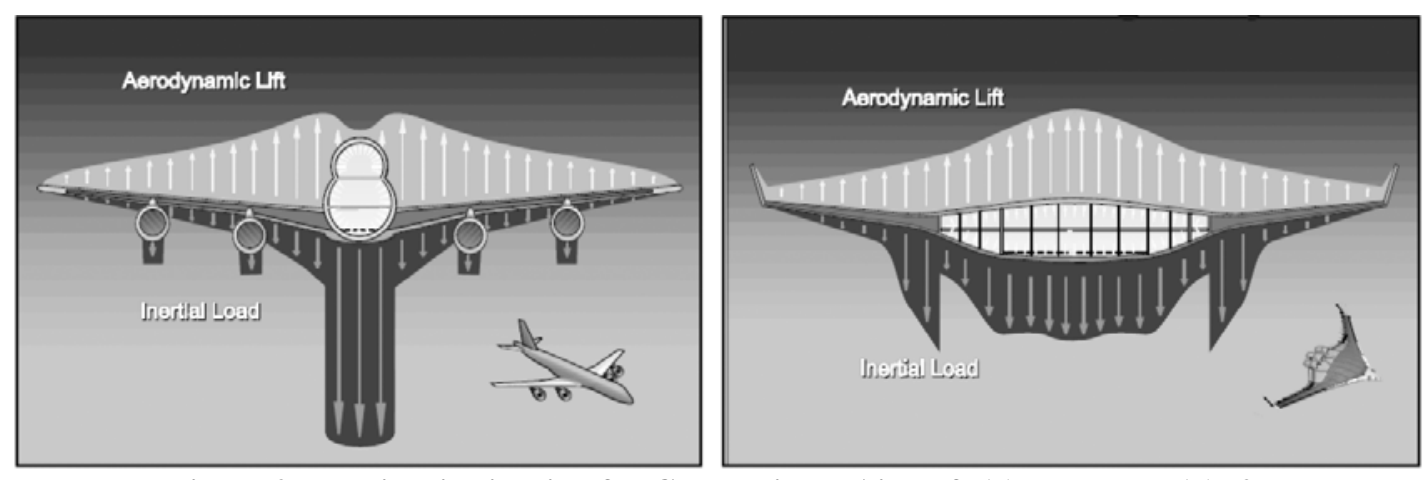

Figure 2. Inertia Distribution for Conventional Aircraft (a) and BWB (b) [2]

The center-body pressure vessel of a BWB needs to be designed for multiple load conditions (aerodynamic loads, pressurization loads, inertia loads etc.). With respect to the BWB-centerbody, two concepts are present in the open literature. The first concept consists of a segregated structure where the pressurization loads are segregated from all other loads. It is depicted in Figure 3a. This concept (also termed “double shell” concept) consists of a thin-walled articulated structure (multibubble) that is designed to carry the pressurization loads. This structure is formed by intersecting circular tubes which are connected by vertical members (walls and/or pillars) between opposite intersection nodes. When the cabin is pressurized, the vertical members and the interior walls are all loaded in tension making this multibubble structure relatively efficient. However, it does require a separate aerodynamic shell which is segregated from the multibubble structure. The aerodynamic and inertia loads are carried through the outer shell structure. The integrated concept (Figure 3b) has the pressure cabin integrated with the centerbody and the pressurization loads are carried via sandwich panels that carry the pressure-induced bending moments. 


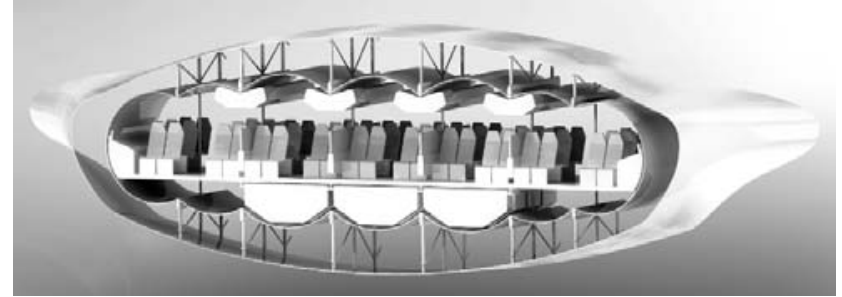

(a) segregated pressure shell concept [4]

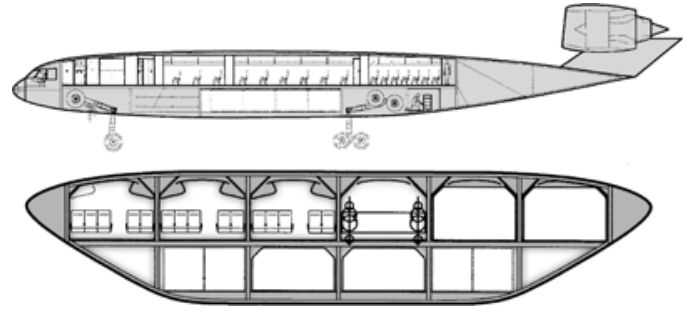

b) integrated skin and shell concept [5]

Figure 3. Two Concepts for BWB Pressurized Cabins

Figure 4 illustrates the stress variation between a circular pressure vessel that transfers the pressurization loads via in-plane loading and a pressure vessel that carries the pressurization loads via a bending moment. In the first instant only in-plane tensile stresses exist, which are equally distributed through the wall thickness. In the latter case, the inside of the wall experiences compressive stresses, while the outside experiences an equal and opposite tensile stress. The maximum stress varies quadratically with the width of the cabin. For a given wall material and fatigue life, the circular section requires a much thinner wall to carry the pressurization loads. This supports the claim that from a structural topology point of view, structures subjected solely to in-plane loading are structurally more efficient than out-of-plane loaded structures. The segregated concept does not however come without its disadvantages. The complexity of a double shell concept where the stresses and deformations need to be segregated from the surrounding structure is high. More information on the segregated and integrated concept is published in [6] .

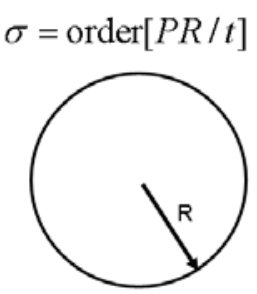

(a)

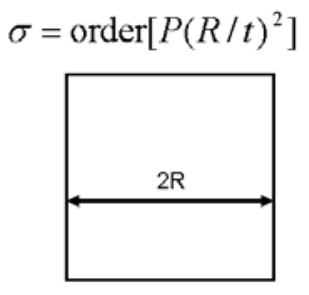

(b)

Figure 4. Variation in Stress Magnitude between a Cylindrical (a) and Rectangular (b) Pressure

\section{Introducing the Oval Centerbody}

\section{A. An Inside-Out Approach to BWB Cabin Design}

Although each of the proposed design solutions to the pressurization problem has its advantages and disadvantages, their commonality lies in the starting point of the design process. Both cabin concepts are designed to fit within a predefined outer surface. It is assumed that this outer surface provides the best shape to fulfill all requirements on handling characteristics while maximizing aerodynamic efficiency. However, if one returns to Equation 1, the required fuel weight is also dependent on the operative empty weight, which, in turn, is dominated by the empty weight of the aircraft. It could therefore be argued that the aerodynamic shape of the centerbody of the BWB should not be dictated by aerodynamic characteristics but that structural weight should be the prime driver for this part of the airframe design. Moreover, the local section lift coefficient at the centerbody is relatively low compared to the outboard wings if an elliptical lift distribution is assumed. Therefore, it seems even more evident that not the aerodynamic design but the structural design should prevail.

Apart from structural and aerodynamic considerations, other considerations with respect to passenger acceptance and cabin configuration come into play. These are difficult to wrap inside a simple analytical formula but play a major role in the (commercial) success of an(y) airplane. The vertical pillars or walls that are specified in both cabin concepts for the BWB put restrictions on cabin configuration. Positioning of chairs, galleys, toilets and other operational items is being constrained by these structural members that invariably penetrate the cabin. Moreover, the 
spaciousness of the wide cabin, which is one of the attractive features of the BWB, is significantly hampered when structural members are positioned. Natural light, coming in through the already sparse number of windows is also prohibited from reaching the center of the body if vertical walls are placed. Given the trend in long-haul wide body airplanes towards larger windows (e.g. Boeing 787) it is unlikely that future airplane designs will feature less natural light, rather than more. From a passenger acceptance and cabin configuration point of view, it would therefore be preferred to have a spacious, naturally-illuminated cabin without vertical pillars or walls interrupting the space.

\section{B. Structural Concept of Oval Cross Section}

With the aforementioned passenger consideration in mind, a new cabin cross section was created that does not have the complexity of a double shell concept and is still able to carry the pressurization loads via in-plane loading. Envision a centerbody cross section as four connecting arcs, two at each side that are identical, one bottom arc and one top arc. In this example the top and bottom arc can have an identical radius of curvature as shown in Figure 5

The resulting cross-section is non-cylindrical, meaning that the curvature of the side arcs are higher than those of the top and bottom arcs. Each of these three arcs can have a different radius of curvature while still allowing for a smooth transition at their connecting nodes. The pressurization of the fuselage cross-section in Figure 5 will only result in in-plane stresses in the fuselage skin of the oval center body. The in-plane stresses result in discrete forces (force $H$ and $V$ in Figure 5b/c) at the connection nodes of the arcs. These discrete forces need to be redistributed with additional structural members to maintain structural integrity. Therefore, each node is connected by 2 additional panels. When pressurized, the long horizontal panels are loaded in compression while the short panels on the side are loaded in tension. In the practical application of this concept the lower horizontal member doubles as the passenger floor. In addition, the upper and lower panes also provide the carry-through structure for the wing torque box at the location of the wing.

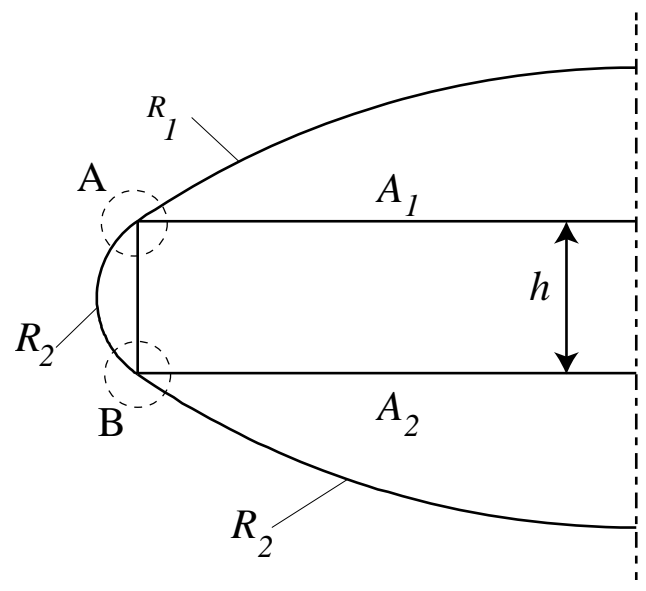

(a) Semi cross section

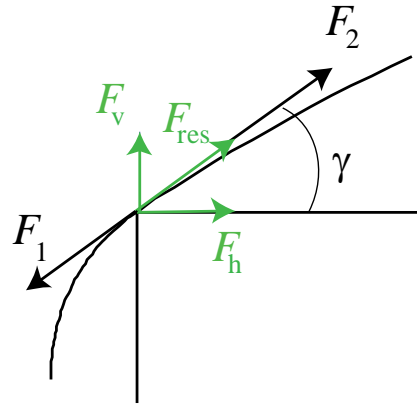

(b) Force balance at $\mathrm{A}$

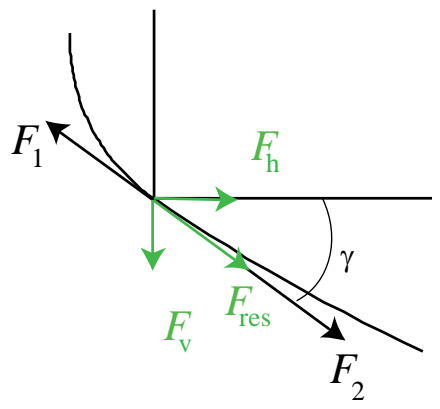

(c) Force balance at B

Figure 5. Cross-section of the oval center body and details

\section{Variations on the Oval Cross Section}

From a structural point of view the absence of bending moments in the structure is beneficial. The vertical tension members can be sized for maximum tensile stresses. The horizontal members are loaded in compression and should therefore be sized for buckling loads. If structural synergy is applied, the floor structure can be sized to withstand the compressive forces. A stiffened panel can be positioned between the lower skin and the floor to increase the buckling resistance. Care must be taken that on the cargo deck sufficient space remains to store the cargo containers. Similarly, a stiffened panel can be placed between the upper compression member and the top skin.

In a preliminary investigation towards the feasibility of the oval cabin concept, the cross section of Figure 6a was designed. As can be seen, the floor is intended to carry the compressive forces. Small LD3-45 containers are fitted side-by-side under the floor. In total 22 seats are positioned next to each other with 5 aisles in between them. The radius of curvature of the top and bottom skin is roughly twice as large as the largest radius of curvature seen in the A380 fuselage. Both cabin cross sections are depicted in Figure 6 for comparison. 


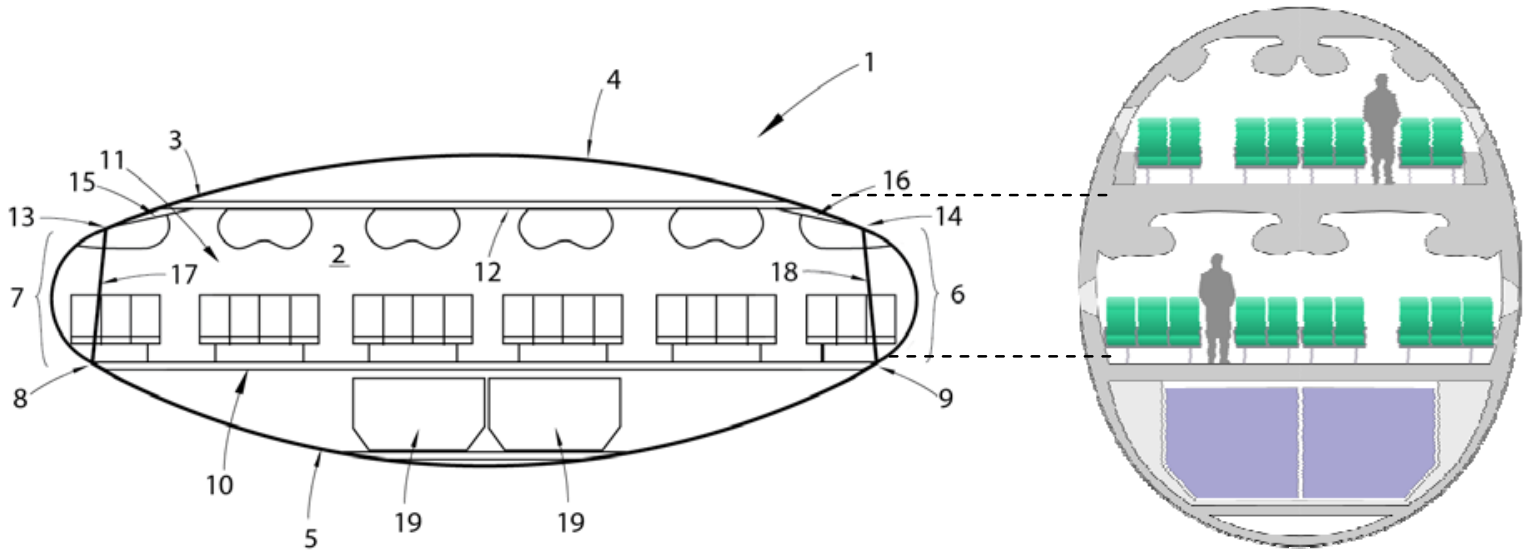

(a) Proposed BWB Cabin Cross Section [8]

(b) A380 Cross Section [8]

Figure 6. Example of cabin cross section

One important variation in the wide oval design of Figure 6(a) is the position of the upper horizontal compression member. To allow for enough passenger head space it has been moved up. Therefore, horizontal forces that appear at the intersecting nodes are to be transferred to this bar by means of short stiffened structure of the fuselage that carries the bending moment that is thus introduced. This way, a trade-off can be made between useful cabin volume and wetted surface area on the one hand, and structural efficiency and weight on the other hand.

Comparing the cabin cross sections of the A380 and the BWB also shows that the available volume is less densely used by the BWB. In particular, the cargo floor allows for smaller unit loading devices to be stowed. It is challenging to match this packing density in the wider cross section for the present geometry of ULDs because they are dimensioned for more circular aircraft cross sections. Other wide-body aircraft such as the 777 suffer from the same lower volume density due to unutilized cabin space above the passenger cabin. The lower deck volume of this BWB cabin could be independently sized from upper deck volume by allowing the lower cabin skin to have a lower radius of curvature than the upper cabin skin. In Figure 6(a) a notional sketch shows how it is possible to do this without violating the requirement on in-plane loading and tangency at the nodes. One can also see the implication for the "vertical" members near the side of the fuselage. Even though these members are now skewed, they still perform the same function as in the symmetric design. It can be seen that the available packing density is significantly increased by using this layout.

\section{Conceptual Design and Weight Estimation}

\section{A. Definition of Design Parameters and Geometry Generation}

A MATLAB program is constructed that allows for the analysis of a blended wing body pressure cabin that at the same time serves as a center fuselage section. The tail section (or aft fuselage) and outer wings still have to be attached to construct the actual aircraft. The cabin is designed from a geometry-input for the surface of the cabin floor, as seen in Figure 7. 


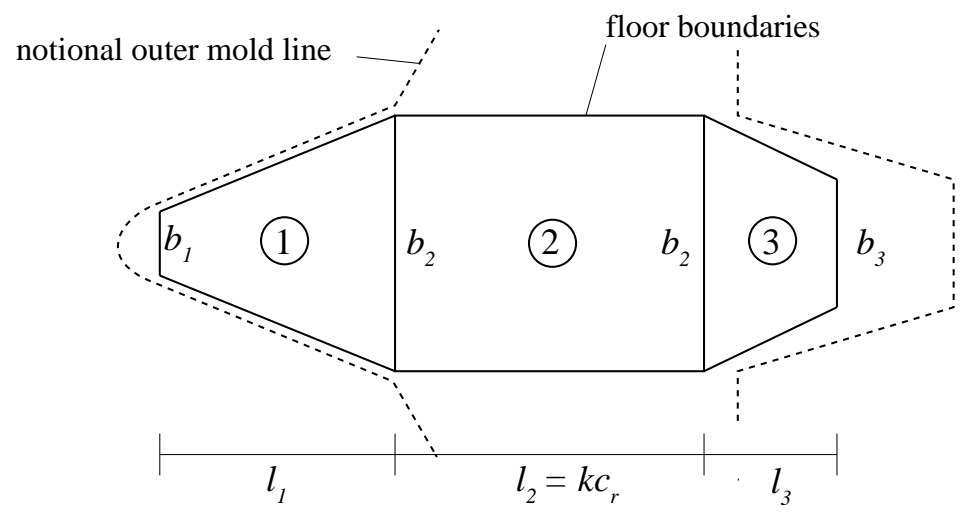

Figure 7. Definition of floor parameters

The geometry is constructed from the parameters shown in Figure 7, i.e. the three characteristic spans $\left(b_{1}, b_{2}, b_{3}\right)$, and the lengths of each section $\left(l_{1}, l_{2}, l_{3}\right)$. The length of section 2 is a fraction of the root chord at the wing attachment point (e.g. $k=0.75$ ). From these six parameters the width of the cabin floor at each fuselage station can be calculated. For the present analysis each of the three sections has been divided into five segments of identical height $(h)$. At the boundaries of each segment the shape of the oval section should be determined. To that extent a symmetric airfoil shape needs to be defined in the symmetry plane of the fuselage. A simple algorithm is capable of finding a combination of $R_{1}$ and $R_{2}$ that satisfies the tangency condition of the intersecting arcs while providing a best fit to the specified airfoil shape. An example of the cabin generation is shown in Figure 8. A modified Whitcomb airfoil with a thickness-to-chord ratio of $17 \%$ is used for demonstration purposes. Furthermore, it has been assumed that the pressure cabin spans $70 \%$ of the local chord, with $28 \%$ of the chord being reserved for the unpressurized aft-fuselage and $2 \%$ of the chord being reserved for the cockpit. Assuming $0.75 \mathrm{~m}^{2}$ per passenger, this cabin provides space to approximately 400 passengers (comparable to a Boeing 777-200 in a two-class configuration). The parameters that were used to generate this cabin are presented in Table 1.
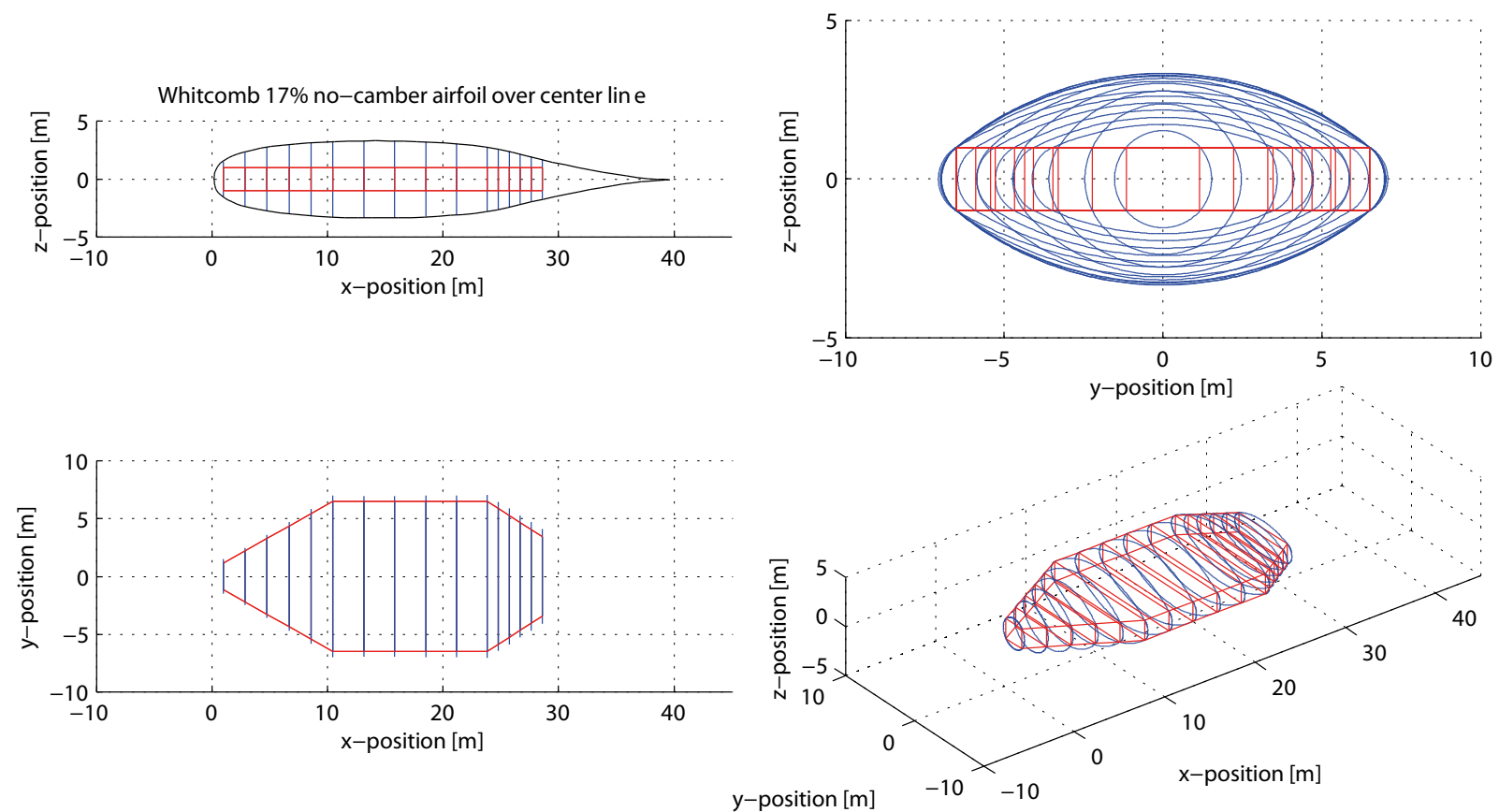

Figure 8. Example of oval blended-wing-body fuselage. Cabin surface area: $294 \mathrm{~m}^{2}$ and cabin width: $\mathbf{1 3 m}$.

In addition to the definition of the cabin height, the definition of the height of the cargo hold $\left(h_{c}\right)$ makes it possible to estimate the surface area available for storing unit loading devices on the lower deck. . In this case a height of 
$1.68 \mathrm{~m}$ has been used, which is the clear-height used for the cargo space of a Boeing 747-400 [10]. For the cabin of Figure 8 this is shown explicitly in Figure 9. For this example it is estimated that approximately 36 LD3 containers can be stored below deck (32 for B777-200). In theory the same amount of containers could also be stored on top of the cabin. With the interpolated data, the available room for a cargo-hold with a specific height can be determined. This is enough to facilitate standard unit load devices. Since the LD3 is the most commonly used container, as it is available on most airports.

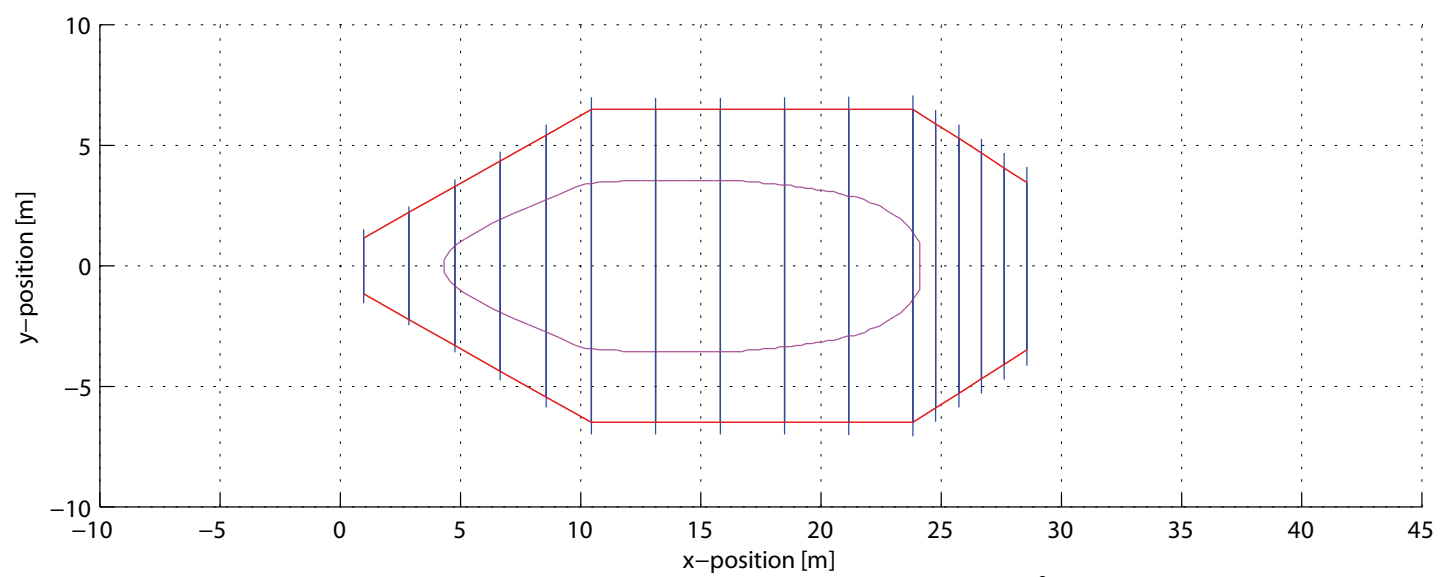

Figure 9. BWB fuselage with cargo floor. Cargo floor area: $113 \mathrm{~m}^{2}$ (36 LD3 containers)

Table 1. Parameters required to generate oval Blended-Wing-Body cabin.

\begin{tabular}{llll}
\hline Parameter & Value & Unit & Description \\
\hline$b_{1}$ & 2.3 & $\mathrm{~m}$ & Floor width aft of cockpit \\
$b_{2}$ & 13.0 & $\mathrm{~m}$ & Floor width of section 2 \\
$b_{3}$ & 6.9 & $\mathrm{~m}$ & Floor width at the end of section 3 \\
$l_{1}$ & 9.5 & $\mathrm{~m}$ & Length of fuselage section 1 \\
$l_{2}$ & 13.4 & $\mathrm{~m}$ & Length of fuselage section 2 \\
$l_{3}$ & 4.7 & $\mathrm{~m}$ & Length of fuselage section 3 \\
$h$ & 2.0 & $\mathrm{~m}$ & Cabin height \\
$h_{c}$ & 1.68 & $\mathrm{~m}$ & Cargo-hold clear height \\
\hline
\end{tabular}

\section{B. Cabin Structural Mass Estimation}

The mass of the fuselage (or BWB center body) cannot be simply obtained from a statistical database on BWB bodies. In this section a first estimation is presented on the cabin weight based on the design parameters of the previous section and a straightforward structural analysis. In this analysis it is assumed that the pressurization loads inducing hoop stresses are driving the required skin thickness of the fuselage. Other load cases, such as longitudinal bending have been omitted in this analysis.

From the definition of the shell geometry, the minimum thickness of each section of the shell, necessary to resist the pressure differential of $\Delta p=80 \mathrm{kPa}$, can be calculated. For this part of the analysis, only the hoop direction is considered. The stress in hoop direction is set to the fatigue stress after 100,000 cycles and a safety factor of $j=1.5$ is included. The thickness then follows from equation (1):

$$
t_{\text {skin }}=\frac{j \Delta p R}{\sigma_{\text {fatigue }}}
$$


The resultant force in the corner can be found through the internal stresses in two sections of the shell. This resultant is tangential to both shells in this corner. A free-body diagram of a corner in the upper-half of the fuselage section is shown in Figure 5 (b). Here, $\Delta l$ is a unit length of a section. The resultant force per unit length is defined as:

$$
\frac{F_{\text {res }}}{\Delta l}=j \Delta p\left(R_{1}-R_{2}\right)
$$

This resultant force per unit length can be split into a component in the horizontal floor and a component in the direction of the vertical wall, as shown in Figure 5(b). The resulting components in horizontal and vertical direction can be determined as follows:

$$
\begin{aligned}
& \frac{F_{\mathrm{h}}}{\Delta l}=\frac{F_{\text {res }}}{\Delta l} \cos \gamma \\
& \frac{F_{\mathrm{v}}}{\Delta l}=\frac{F_{\text {res }}}{\Delta l} \sin \gamma
\end{aligned}
$$

If we assume that the maximum allowable stress in the vertical walls is governed by fatigue properties of the selected material we can define the thickness of these walls as follows:

$$
t_{\text {wall }}=\frac{F_{\mathrm{v}}}{\sigma_{\text {fatigue }} \Delta l}
$$

The horizontal sandwich panels are sized for buckling. Since the same horizontal force is applied on both sides of the panel, the critical buckling force is determined by:

$$
F_{\text {crit }}=\frac{\pi^{2} E_{f} I_{f}}{b^{2}}
$$

Where $L$ is the length of the sandwich panel (the width of the ceiling or floor) and the second moment of area, $I_{f}$ of both facings of the panel:

$$
I_{f}=\Delta l\left[\frac{1}{6} t_{f}^{3}+\frac{1}{2} t_{f}\left(t_{c}+t_{f}\right)^{2}\right]
$$

In Equation (7) $t_{c}$ is the thickness of the core. The contribution of the core to the buckling stiffness of the panels is neglected. The combination of $t_{f}$ and $t_{c}$ that is finally selected for the sandwich panel is the combination that yields the minimum mass while withstanding the horizontal component of the resultant force in buckling. This is done through minimizing the specific mass in equation (8) while both $t_{f}$ and $t_{c}$ must be real and positive.

$$
\text { minimize }
$$$$
J=2 t_{f} \rho_{f}+t_{c} \rho_{\text {core }}
$$$$
\text { subject to }
$$

$$
\begin{aligned}
& \frac{F_{\mathrm{h}}}{\Delta l}-\frac{\pi^{2} E_{f}}{b^{2}}\left[\frac{1}{6} t_{f}^{3}+\frac{1}{2} t_{f}\left(t_{c}+t_{f}\right)^{2}\right]<0 \\
& -t_{f}<0 \\
& -t_{c}<0
\end{aligned}
$$

With all dimensions of the components of the shell and floors and ceilings determined, the mass per unit fuselage length can be computed. The mass per unit fuselage length at each station is a summation of the various components. The total mass of the cabin is computed by taking sum of the average mass per unit length between two stations along the fuselage length and multiplying this with the distance between the two stations. For the cabin design of Figure 8 and the parameters of Table 1 the structural weight of this cabin is estimated to be 34.1 metric tons. The weight distribution over the cabin is presented in . 
Table 2. Input parameters for weight estimation.

\begin{tabular}{llll}
\hline Parameter & Value & Unit & Description \\
\hline$\Delta p$ & 80 & $\mathrm{kPa}$ & Cabin pressure differential \\
$\rho_{\mathrm{al}}$ & 2770 & $\mathrm{~kg} / \mathrm{m}^{3}$ & Density of all aluminum components (AL2024T6) [11] \\
$E_{\mathrm{al}}$ & 73.8 & $\mathrm{GPa}$ & AL2024T6 tensile modulus of elasticity [11] \\
$\sigma_{\text {faigue }}$ & 135 & $\mathrm{MPa}$ & AL2024T6 fatigue strength at 100,000 cycles [11] \\
$j$ & 1.5 & - & Safety factor \\
$\rho_{c}$ & 50 & $\mathrm{~kg} / \mathrm{m}^{3}$ & Aluminum honeycomb \\
$t_{f}$ & $1-15$ & $\mathrm{~mm}$ & Range of evaluated facing thicknesses \\
\hline
\end{tabular}

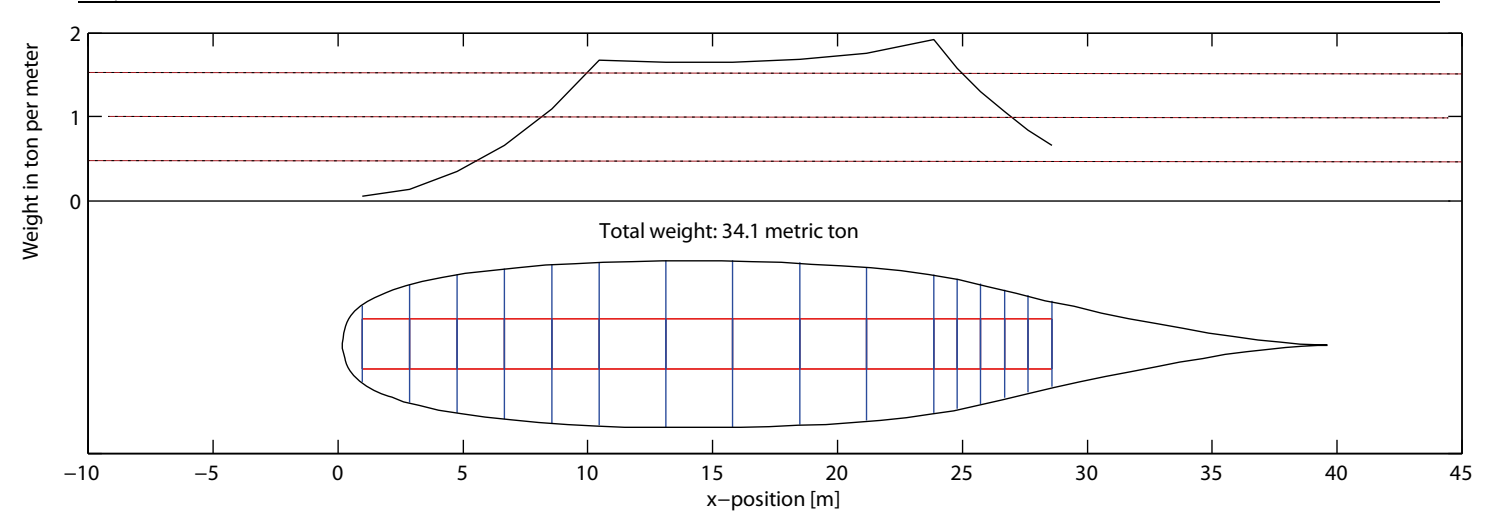

Figure 10. Distribution of Structural Cabin Weight.

Further research is ongoing in the prediction of the entire fuselage weight including non-structural components and the components outside the cabin area (e.g. cockpit and aft-fuselage). Furthermore, load cases stemming from the wing bending moment, the longitudinal moment due to weight distribution, and aerodynamic loads are to be incorporated. However, due to the large radii of curvature found throughout a large part of the cabin, it is expected that the pressurization loads will be dominant for the required material thickness. Another refinement in future weight estimations is the possibility to specify composite materials rather than isotropic materials.

\section{Aerodynamic Design}

\section{A. Centerbody Lift}

To minimize the lift-induced drag over any high-subsonic aircraft an elliptical lift distribution is desired. For the planform shape of a typical BWB this implies that the lift coefficient over the center section needs to be lowest (on the order of 0.1 in cruise conditions). To generate such a low lift coefficient at high-subsonic Mach numbers does not necessarily require the application of supercritical airfoils. As a matter of fact, many airfoil shapes can be found suitable for producing this lift coefficient without generating shock waves. It is anticipated that the modified Whitcomb that has been used in the example in this paper could therefore also be replaced by alternative airfoil shapes in favor of weight decrease. This qualitative assessment on the section lift-coefficient requirement of the centerbody was one of the justifications for allowing a more weight-driven shape of the centerbody.

\section{B. Wing-Body Interference}

To investigate whether such a cross section is capable of forming a feasible three-dimensional cabin structure, the oval cross section was tailored to meet specified planform and wing section constraints. A typical BWB planform was used with a leading edge sweep angle of 66 degrees. The perimeter of the cabin's vertical symmetry plane was prescribed by a symmetrical NACA 7-series airfoil. This dictated the radii of curvature of each of the arcs of the 
cross section, providing that smoothness was conserved at the intersecting nodes. Figure 11 shows the oval centerbody in three dimensions. In addition, small notional wing trunks have been added to demonstrate the nonsmooth interface between wing and body. The oval centerbody cross section does not allow for a smooth transition which requires the addition of aerodynamic fairings to reduce interference drag at high subsonic Mach numbers. The sizing of these fairings is to be investigated during a preliminary design exercise. It is acknowledged that the fairings will add weight to the structure.

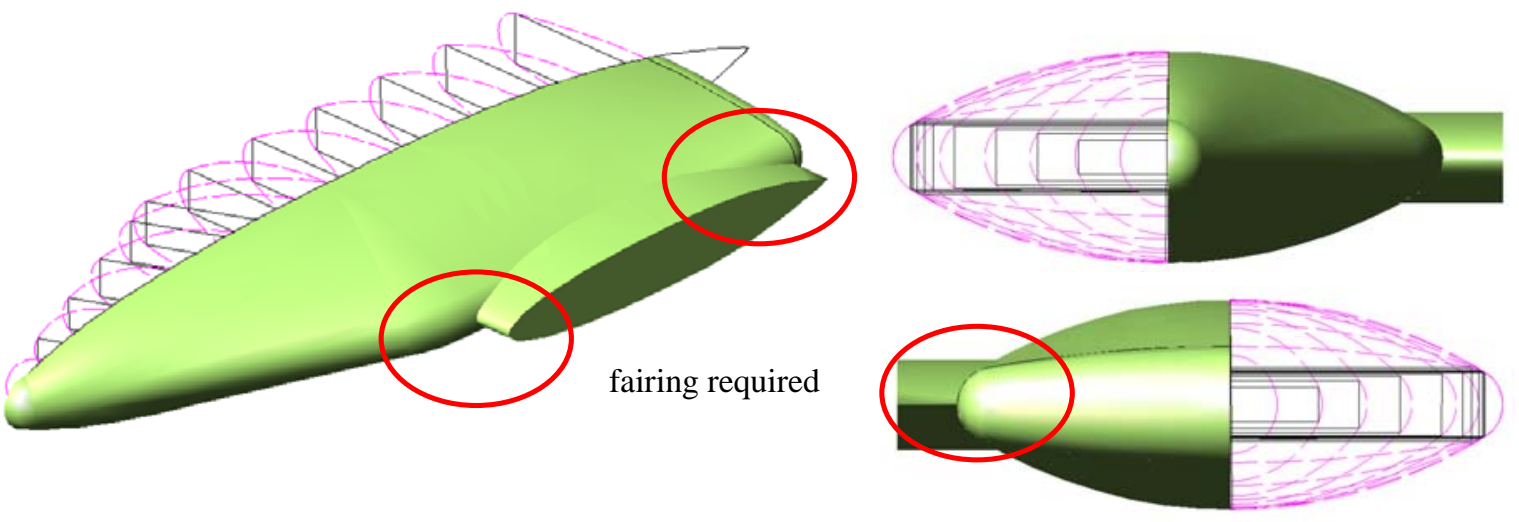

Figure 11. The BWB with oval centerbody in 3d, front, and rear-view

\section{Discussion of Oval BWB Fuselage Concepts}

The present paper presents a new structural design for a blended-wing body fuselage. Due the absence of thorough analysis a quantitative comparison between the integrated and segregated concepts cannot be made at this stage. However, it is meaningful to compare these three different concepts on a qualitative basis to support the claim that this new design holds any merit. Such a qualitative analysis has been carried out through the best judgment of the authors. The result of this endeavor is displayed in Table 3.

Table 3. Qualitative Comparison of Fuselage Concepts

\begin{tabular}{|c|c|c|c|}
\hline & Integrated & Segregated & Oval \\
\hline 胥 & $\begin{array}{l}\text { The integration of the pressure vessel } \\
\text { and the aerodynamic shell yields a } \\
\text { simple solution that mimics } \\
\text { conventional aircraft today. Benefits } \\
\text { of this configuration will be } \\
\text { harnessed during the manufacturing } \\
\text { process. }\end{array}$ & $\begin{array}{l}\text { The structural implementation of a } \\
\text { segregated pressure vessel with the } \\
\text { aerodynamic shell becomes more } \\
\text { complex as the aerodynamic shell } \\
\text { and the segregated pressure vessel } \\
\text { will undergo different deformations. } \\
\text { In this configuration a solution must } \\
\text { be implemented to house the multi- } \\
\text { bubble within the structure. }\end{array}$ & $\begin{array}{l}\text { The complexity of this solution is } \\
\text { found in every design phase where a } \\
\text { good compromise needs to be found } \\
\text { between aerodynamic efficiency, } \\
\text { structural efficiency and payload } \\
\text { capacity. Compared to the other } \\
\text { concepts, the amount of wasted } \\
\text { pressurized space is larger, especially } \\
\text { w.r.t. the integrated concept. }\end{array}$ \\
\hline 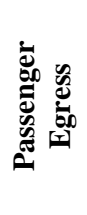 & $\begin{array}{l}\text { The passenger egress from the } \\
\text { integrated solution is similar to that } \\
\text { in conventional aircraft. Exit cut outs } \\
\text { only need to be made in the outer } \\
\text { structure. }\end{array}$ & $\begin{array}{l}\text { Passenger egress from the segregated } \\
\text { solution is a more complex matter. } \\
\text { Cut outs have to be made in both the } \\
\text { aerodynamic shell and the multi- } \\
\text { bubble structure with a flexible } \\
\text { corridor structure in between. }\end{array}$ & $\begin{array}{l}\text { The passenger egress from the } \\
\text { integrated solution is similar to that } \\
\text { in conventional aircraft. Exit cut outs } \\
\text { only need to be made in the outer } \\
\text { structure. }\end{array}$ \\
\hline
\end{tabular}


It is expected that the pressure altitude in the pressure cabin will be around $75 \mathrm{kPa}$ at cruise altitude, similar to conventional aircraft. Increasing the pressure reduces the structural efficiency and therefore decreases the fuel efficiency.

The pressure cabin is interrupted by structural members which has a negative influence on the passenger orientation. However, reducing the structural members that penetrate the cabin reduces the structural efficiency. A compromise needs to be found.
Passengers can easily fly at sea-level altitude in the multi-bubble cabin which gives a more comfortable environment.

The pressure cabin is interrupted by structural members which has a negative influence on the passenger orientation. However, reducing the structural members that penetrate the cabin reduces the structural efficiency. A compromise needs to be found.
It is expected that the pressure altitude in the pressure cabin will be around $75 \mathrm{kPa}$ at cruise altitude, similar to conventional aircraft. Increasing the pressure reduces the structural efficiency and therefore decreases the fuel efficiency.

Passengers have an uninterrupted view in the pressure cabin which enhances the passenger orientation and acceptance. The airliner can optimize the cabin configuration to maximize passenger comfort without being restrained by walls. Natural light can also travel throughout the cabin, which also increases the chance of passenger acceptance.

The weight penalty becomes relatively large with respect to the other concepts when the radii of the fuselage panels increase. Structural instabilities in the compressed floor and ceiling lead to large weight penalties. This concept seems to be especially interesting when the BWB is relatively small (pressure cabin widths in between $10-15 \mathrm{~m}$ ).
The structure is subjected to bending moments which is detrimental for the distorts the surface of the aerodynamic shell. The integrated solution is pressurized near the limit loading on every flight which leads to over-dimensioning in order to cope with fatigue issues
Should theoretically give the highes structural efficiency but the structural implementation of two segregated structures will lead to weight penalties. The gain of the segregation becomes higher when the size of the centerbody is increasing. There are no distortions in the aerodynamic surface during normal flight conditions which is a big advantage.

\begin{tabular}{|c|c|c|c|}
\hline $\begin{array}{l}\text { The shape of the cabin is optimized } \\
\text { for aerodynamic efficiency. It is } \\
\text { therefore expected that the } \\
\text { aerodynamic efficiency is } \\
\text { maximized. }\end{array}$ & $\begin{array}{l}\text { The shape of the cabin is optimize } \\
\text { for aerodynamic efficiency. It } \\
\text { therefore expected that tl } \\
\text { aerodynamic efficiency } \\
\text { maximized. }\end{array}$ & & $\begin{array}{l}\text { The aerodynamic design is } \\
\text { compromised by structural and } \\
\text { operational requirements. Fairings } \\
\text { between cabin and the outer wings } \\
\text { need to be added to prevent } \\
\text { interference drag penalties. }\end{array}$ \\
\hline
\end{tabular}

\section{Conclusions \& Future Research}

A notional overview of a new oval cabin design for the blended wing body has been presented. This design relies on connecting arcs of various radii of curvature to carry the pressurization loads. An internal box structure carries the in-plane compression and tension loads. It has been shown how this cross-sectional concept could be structurally efficient and allow for a large uninterrupted cabin space. Furthermore, it has been shown how the geometry can be tailored to meet requirements on cargo stowage and passenger accommodation. A first weight estimation has been developed to predict the total cabin weight as a function of its main dimensional parameters. A qualitative comparison between the alternative designs shows that this new concept scores particularly well in customer acceptance due to the flexibility in cabin configuration.. Additional research is tailored to developing better weight estimation tools, investigate the structural and aerodynamic interconnection between outer wing and main cabin, and evaluate the overall performance of BWB aircraft with an oval centerbody.

\section{References}

[1] Torenbeek, E., “Aerodynamic Performance of Wing-Body Configurations and the Flying Wing,” presented at General, Corporate and Regional Aviation Meeting and Exposition, ASME, Wichita, KS, April 1st 1991.

[2] Liebeck, R.H., "Design of the Blended Wing Body Subsonic Transport,” The Boeing Company, Huntington Beach, California 92647, Journal of Aircraft Vol. 41, No. 1, January-February 2004, pp. 10-25. 
[3] Spakovszky, Z.S., “Toward a "Silent” Aircraft,” The Cambridge-MIT Institute, $22^{\text {nd }}$ Symposium on Aviation Noise and Air Quality, San Francisco CA, 2007.

[4] Van der Voet, Z. "Conceptualisation of a future passenger aircraft Interior using a non-cylindrical pressure fuselage,” Graduation thesis, Delft University of Technology, the Netherlands, 2009.

[5] Mukhopadhyay, V., Sobieszczanski-Sobieski, J., Kosaka, I., Quinn, G., Vanderplaats, G.N., “Analysis, Design, and Optimization of Noncylindrical Fuselage for Blended-Wing-Body Vehicle,” Journal of Aircraft, Vol.41, No. 4, July 2004.

[6] Martinez-Val, R., “Flying Wings. A New Paradigm for Civil Aviation?”Acta Polytechnica, Vol. 47 No.1, 2007.

[7] McInally, “The Investigation and Conceptual Structural Topology Design of a Commercial Blended Wing Body Aircraft,” Graduation thesis, Delft University of Technology, the Netherlands, 2011

[8] Vos, R., Geuskens, F.J.J.M.M., “Aircraft Fuselage,” Patent pending, N2007397, September 12 2011.

[9] Tillier, C., “Airbus A380 Cross Section,” accessed from www.wikipedia.org/Airbus_A380 on August 24th, 2011.

[10] Anon. “747-400 Airplane Characteristics for Airport Planning,” Boeing Commercial Airplanes, D6-58326-1, 2002.

[11] Anon. “CES Edupack 2011,” Granta, Cambridge, UK, 2011. 